\title{
Bidi and Hookah Use Among Canadian Youth: Findings From the 2010 Canadian Youth Smoking Survey
}

Christine D Czoli, BSc; Scott T Leatherdale, PhD; Vicki Rynard, MSc

Suggested citation for this article: Czoli CD, Leatherdale ST, Rynard V. Bidi and Hookah Use Among Canadian Youth: Findings From the 2010 Canadian Youth Smoking Survey. Prev Chronic Dis 2013;10:120290. DOI: http://dx.doi.org/10.5888/pcd10.120290 国.

PEER REVIEWED

\section{Abstract}

\section{Introduction}

Although cigarette use among Canadian youth has decreased significantly in recent years, alternative forms of tobacco use are becoming increasingly popular. Surveillance of youth tobacco use can help inform prevention programs by monitoring trends in risk behaviors. We examined the prevalence of bidi and hookah use and factors associated with their use among Canadian youth by using data from the 2010-2011 Youth Smoking Survey (YSS).

\section{Methods}

We analyzed YSS data from 28,416 students (2006-2007) and 31,396 students (2010-2011) in grades 9 through 12 to examine prevalence of bidi and hookah use. We conducted multivariate logistic regression analyses of 2010-2011 YSS data to examine factors associated with bidi and hookah use.

\section{Results}

From 2006 through 2010, prevalence of hookah use among Canadian youth increased by $6 \%(P=.02)$. Marijuana use emerged as a consistent predictor of bidi and hookah use. Males, youth of black, Latin, or other descent, and youth of Asian descent were more likely to use bidis (odds ratio [OR], 1.5; OR, 15.6; OR, 14.9) or hookah (OR, 1.3; OR, 2.4; OR, 1.5). Current cigarette smokers were more likely than nonsmokers to be current users of bidis (OR, 6.7) and hookahs (OR, 3.0), and occasional and frequent alcohol drinkers were also more likely than nondrinkers to be current hookah users (OR, 2.8; OR, 3.6).

\section{Conclusion}

Although bidi use has not changed significantly among Canadian youth, the increase in hookah use warrants attention. Understanding the factors associated with use of bidis and hookahs can inform the development of tobacco use prevention programs to address emerging at-risk youth populations.

\section{Introduction}

In recent years, patterns of global tobacco use among youth have changed substantially. Although cigarette use has decreased significantly, alternative forms of tobacco are becoming increasingly popular (1). In Canada, although cigarette smoking among youth decreased from $28.0 \%$ in 1999 to $12.0 \%$ in 2010 (2), data on the use of alternative tobacco products are limited. Many alternative tobacco products, including bidis and hookahs, pose significant health risks and sustain nicotine dependence $(1,3,4)$. Furthermore, the popularity and perceptions of reduced harm associated with these products among youth and young adults have generated serious public health concern (5-7).

Bidi cigarettes contain tobacco hand-rolled in tendu leaf and look like hand-rolled marijuana cigarettes $(4,8)$. According to the 2006-2007 Canadian Youth Smoking Survey (YSS) (8), 1.7\% of Canadian youth had ever used bidis and $0.7 \%$ were current users. Sex, smoking status, marijuana use, alcohol use, race/ethnicity, level of education, exposure to peers who smoke, and depressive symptoms are associated with bidi use among youth and young adults (8 $-11)$. 
Hookah, a water pipe that is used to smoke tobacco, originated in the Middle East (12). According to the 2006-2007 YSS, 6.8\% of Canadian students reported ever using hookahs, and 2.7\% were current users in 2006 (8). Existing evidence suggests that youth are more likely to use hookahs if they are male, smoke cigarettes, use marijuana or alcohol (8), know of a hookah lounge in the community, or believe that hookahs are more socially acceptable than cigarettes $(13,14)$.

A better understanding of bidi and hookah use among youth is important for the development of future initiatives to prevent tobacco use. Ongoing surveillance of tobacco use among Canadian youth has not examined these issues since 2006 (8). We examined the prevalence of bidi and hookah use and associated factors among Canadian youth in 2010 and trends in prevalence since 2006.

\section{Methods}

We used representative data collected from 31,396 Canadian students in grades 9 through 12 from 176 schools as part of the 2010-2011 YSS. The target population for the data used in this study consisted of all young Canadian residents in grades 9 through 12 attending public, private, and Catholic schools in 9 of the 10 Canadian provinces. Youth living in New Brunswick, Yukon, Nunavut, and the Northwest Territories were excluded from the target population, as were youth living in institutions or on First Nation Reserves and youth attending special schools or schools on military bases. The YSS was administered to students during class time, and participants were not compensated. The survey design and sample weights allow us to produce the population-based estimates in this article. Further details regarding recruitment and data collection for the YSS are available (15).

A combination of active information-passive permission and active permission protocols was used to recruit students. Active information-passive permission protocols required that parents call a toll-free number if they did not want their child to participate in the study after they had read an information letter describing the project, whereas active permission protocols required that students return a permission form signed by a parent or guardian. Students also had the opportunity to decline participation on the day of data collection. The response rate at the student level for the full 2010-2011 YSS (including students from grades 6 through 12) was 73.0\% (15). The University of Waterloo Office of Research Ethics and appropriate school board and public health ethics committees approved all procedures, including passive consent.

Ever use of hookahs and bidis was measured by asking respondents to report if they had ever tried 1) using a water pipe to smoke tobacco (also known as a hookah, sheesha, narg-eelay, hubble-bubble, or gouza), or 2) smoking bidis (little cigarettes that are hand-rolled in leaves, tied with a string at the ends, and come in different flavors). Current use of hookahs and bidis was measured by asking respondents if in the last 30 days they had used 1) a water pipe to smoke tobacco (also known as a hookah, sheesha, narg-eelay, hubble-bubble, or gouza), or 2) bidis (little cigarettes that are hand-rolled in leaves, tied with a string at the ends, and come in different flavors).

Consistent with Health Canada's definitions of smoking status for the YSS (16), smoking status was measured by asking respondents if they had ever smoked 100 or more whole cigarettes in their lifetime, and on how many of the last 30 days they smoked 1 or more cigarettes. Current smokers had smoked 100 cigarettes in their lifetime and had smoked in the previous 30 days; former smokers had smoked 100 cigarettes in their lifetime but had not smoked in the previous 30 days; and nonsmokers had smoked fewer than 100 cigarettes in their lifetime (15). The YSS also collected information on use of flavored tobacco products. Ever use of flavored tobacco products was measured by asking respondents if they had ever used flavored tobacco products (eg, menthol, cherry, strawberry, vanilla). Current use of flavored tobacco products was measured by asking respondents to check off the flavored tobacco products they had used in the last 30 days from a list (menthol cigarette, flavored cigarillo or little cigar, flavored cigar, flavored bidi, flavored smokeless tobacco, flavored tobacco in a water pipe). Marijuana use was assessed by asking respondents, "In the last 12 months, how often did you use marijuana or cannabis? (a joint, pot, weed, hash ...)". Those who reported never or not in the last 12 months were considered nonusers, those who reported using marijuana in the last year but not weekly were occasional users, and those who reported using marijuana weekly were considered frequent users. Alcohol use (binge drinking) was assessed by asking respondents, "In the last 12 months, how often did you have 5 drinks of alcohol or more on 1 occasion?" Those who reported never or not in the last 12 months were nonusers, those who reported binge drinking in the last year but not weekly were occasional drinkers, and those who reported binge drinking weekly were considered frequent drinkers. Demographic characteristics and further details regarding the 2010-2011 YSS questionnaire are available online (17).

Survey weights were used in all analyses to adjust for differential response rates across regions or groups and to adjust for complex sampling. Survey weights were developed in 2 stages. In the first stage, a weight (W1j) was created to account for the school selection within health region and school strata. In the second stage, another weight (W2jg) was calculated to adjust for student nonresponse. The weights were then calibrated to the provincial sex and grade distribution so that the total of the survey weights by sex, grade, and province would equal the actual enrollments in those groups. Descriptive analyses of the sample characteristics were examined by bidi ever use, bidi current use, 
hookah ever use, and hookah current use, using weighted data. Changes in prevalence of bidi and hookah ever and current use from 2006 through 2010 were also examined. We used data collected from 28,416 respondents in the 2006 -2007 YSS, which was sampled, conducted, and weighted by using methods equivalent to those employed in 20102011. We then conducted 4 multivariate logistic regression models to examine factors associated with bidi ever use, hookah ever use, bidi current use, and hookah current use. SAS version 9.2 (SAS Institute Inc, Cary, North Carolina) was used for all analyses. Significance was set at $P<.05$.

\section{Results}

Sample characteristics have been described previously (18). We calculated descriptive statistics for 2010 by examining bidi and hookah use among Canadian youth in grades 9 through 12 (Table 1), changes in the prevalence of bidi and hookah use from 2006 through 2010 (Table 2), and the results of logistic regression for factors associated with bidi and hookah use (Table 3).

\section{Ever use of bidis}

Only $1.8 \%$ ( $n=29,400)$ of Canadian youth in grades 9 through 12 in 2010 reported ever smoking bidis. Rates of bidi ever use were significantly higher in Atlantic Canada and the Prairies than in Ontario and Quebec $\left(\chi^{2}=79.2\right.$, degrees of freedom $(d f)=4, P<.001)$. Ever use of bidis was higher among respondents reporting ever use of flavored tobacco products $\left(\chi^{2}=1,099.4, d f=1, P<.001\right)$ and among respondents who report current use of flavored tobacco in a water pipe $\left(\chi^{2}=2,645.9, d f=1, P<.001\right)$. From 2006 through 2010, the prevalence of youth having ever smoked bidis decreased significantly by $18.2 \%$ and declined significantly more among female respondents (33.3\%) than male respondents (10.3\%).

As shown in Model 1 (Table 3), compared with female youth, male youth were more likely to have ever used bidis (odds ratio $[\mathrm{OR}], 2.5 ; 95 \%$ confidence interval [CI], 2.0-3.1). Compared with white respondents, students who self-identified as black, Latin, or other (OR, 4.6; 95\% CI, 3.7-5.8) or Asian (OR, 3.2; 95\% CI, 2.2-4.7) were more likely to have ever used bidis. Compared with nonsmokers, former cigarette smokers (OR, 1.9; 95\% CI, 1.2-3.1) and current cigarette smokers (OR, 4.1; 95\% CI, 3.3-5.2) were more likely to have ever used bidis. Occasional marijuana users (OR, 4.9; 95\% $\mathrm{CI}, 3.3-7.2)$ and frequent marijuana users (OR, 13.1; 95\% CI, 9.0-19.1) were more likely than nonusers to be ever users of bidis. Frequent alcohol drinkers were also more likely to be bidi ever users (OR, 2.2; 95\% CI, 1.5-3.4) than were nondrinkers.

\section{Current use of bidis}

Only 1.0\% $(n=15,100)$ of Canadian youth in grades 9 through 12 in 2010 reported currently smoking bidis. Current bidi use was significantly lower in grade 10 than in grades 9,11 , and $12\left(\chi^{2}=18.8, d f=3, P<.001\right)$. Rates of current bidi use were significantly higher in Atlantic Canada and the Prairies than in Ontario and Quebec $\left(\chi^{2}=64.0, d f=4, P\right.$ $<$.001). Current bidi use was higher among respondents reporting ever use of flavored tobacco products $\left(\chi^{2}=578.1, d f\right.$ $=1, P<.001)$ and among respondents who reported current use of flavored tobacco in a water pipe $\left(\chi^{2}=3,800.1, d f=\right.$ $1, P<.001)$. From 2006 through 2010, the prevalence of youth currently using bidis increased by $25.0 \%$ and increased substantially more among female (50.0\%) than male (8.3\%) respondents.

As shown in Model 2 (Table 3), compared with female youth, male youth were more likely to be current bidi users (OR, 1.5; 95\% CI, 1.1-2.1). Compared with white respondents, those who self-identified as black, Latin, or other (OR, 15.6; 95\% CI, 10.8-22.5), Asian (OR, 14.9; 95\% CI, 8.9-24.9), or Aboriginal (OR, 3.3; 95\% CI, 1.9-5.7) were more likely to be current bidi users. Former cigarette smokers were less likely than nonsmokers to be current bidi users (OR, o.2; 95\% CI, O-0.7), whereas current cigarette smokers were more likely to be current bidi users (OR, 6.7; 95\% CI, 4.89.5). Respondents who smoke marijuana occasionally (OR, 23.9; 95\% CI, 10.8-53.0) or frequently (OR, 50.4; 95\% CI, 22.9-111.0) were significantly more likely than marijuana nonsmokers to be current bidi users. Occasional alcohol drinkers were less likely to be current bidi users (OR, 0.4; 95\% CI, 0.2-0.7) than were nondrinkers.

\section{Ever use of hookahs}

In Canada, $10.1 \%(\mathrm{n}=161,300)$ of youth in grades 9 through 12 in 2010 reported ever using a hookah. Ever use of hookahs increased significantly by grade $\left(\chi^{2}=535.9, d f=3, P<.001\right)$. Rates of hookah ever use were significantly higher in Quebec and British Columbia than in Atlantic Canada and Ontario $\left(\chi^{2}=107.5, d f=4, P<.001\right)$. Ever use of hookah was higher among respondents reporting ever use of flavored tobacco products $\left(\chi^{2}=5,642.0, d f=1, P<.001\right)$ and among respondents who reported current use of flavored bidis $\left(\chi^{2}=1,063.6, d f=1, P<.001\right)$. From 2006 through 2010 , the prevalence of youth having ever smoked hookahs increased significantly by $6.3 \%$, and a substantially larger increase was evident among female youth (10.4\%) than male youth (3.6\%).

As shown in Model 3 (Table 3), compared with whites, respondents who self-identified as black, Latin, or other (OR, 2.2; 95\% CI, 1.9-2.5) or Asian (OR, 1.5; 95\% CI, 1.3-1.8) were more likely to have ever used hookahs, whereas Aboriginal respondents were less likely to have ever used hookahs (OR, 0.6; 95\% CI, 0.5-0.7). Former cigarette 
smokers (OR, 5.5; 95\% CI, 4.4-6.9) and current cigarette smokers (OR, 2.4; 95\% CI, 2.1-2.6) were more likely than nonsmokers to have ever used hookahs. Respondents who were occasional marijuana users (OR, 4.8; 95\% CI, 4.2-5.4) and frequent marijuana users (OR, 11.6; 95\% CI, 10.1-13.3) were more likely to be ever users of hookahs. Compared with nondrinkers, occasional alcohol drinkers (OR, 2.5; 95\% CI, 2.1-3.0) and frequent alcohol drinkers (OR, 3.3; 95\% CI, 2.8-4.0) were more likely to be ever users of hookahs.

\section{Current use of hookahs}

In $2010,4.0 \%(n=62,900)$ of Canadian youth in grades 9 through 12 reported currently using hookahs. Current hookah use increased significantly by grade $\left(\chi^{2}=194.0 ; d f=3, P<.001\right)$ and was higher among respondents reporting ever use of flavored tobacco products $\left(\chi^{2}=2,495.7, d f=1, P<.001\right)$ and current use of flavored bidis $\left(\chi^{2}=2,793.9, d f=\right.$ $1, P<$.001). From 2006 through 2010, the prevalence of current hookah use increased by only $2.6 \%$; the prevalence among female respondents increased significantly by $16.0 \%$, whereas the prevalence among male respondents decreased by $2.0 \%$.

As shown in Model 4 (Table 3), male youth were more likely than female youth to be current hookah users (OR, 1.3; 95\% CI, 1.1-1.4). Compared with whites, respondents who self-identified as black, Latin, or other (OR, 2.4; 95\% CI, 2.1 -2.9) or Asian (OR, 1.5; 95\% CI, 1.2-2.0) were more likely to be current hookah users. Compared with nonsmokers, former cigarette smokers (OR, 3.3; 95\% CI, 2.5-4.4) and current cigarette smokers (OR, 3.0; 95\% CI, 2.5-3.5) were more likely to be current hookah users. Respondents who smoke marijuana occasionally (OR, 5.6; 95\% CI, 4.4-7.1) or frequently (OR, 14.1; 95\% CI, 11.1-18.0) were significantly more likely than marijuana nonsmokers to be current hookah users. Compared with nondrinkers, occasional alcohol drinkers (OR, 2.8; 95\% CI, 2.1-3.8) and frequent alcohol drinkers (OR, 3.6; 95\% CI, 2.7-5.0) were more likely to be current hookah users.

\section{Discussion}

From 2006 through 2010, the prevalence of both ever and current hookah use among Canadian youth increased. This finding is consistent with global trends marking the spread of hookah use among youth (12). Change in bidi use among Canadian youth from 2006 through 2010 was less concerning; ever use decreased significantly and current use increased modestly. Prevalence of current bidi use is similar among Canadian and American youth (9). Surveillance of such trends is critical to the development of tobacco control interventions that appropriately address the changing context of youth tobacco use patterns. Youth interventions should address the shift from cigarette use to use of alternative tobacco products; in the face of resource constraints, tobacco control efforts should focus on the rise in hookah use rather than use of bidis.

Marijuana use emerged as a consistent predictor of bidi and hookah use among Canadian youth. Occasional and frequent smokers of marijuana were more likely than nonsmokers to use or have used bidis or hookahs. These findings are consistent with existing research $(8,10,19,20)$. Delnevo and Hrywna found a strong association between use of bidis and use of marijuana and blunts (cigars used for smoking marijuana by replacing some or all of the filler with marijuana), which may be explained by visual and perceived similarities between bidis and marijuana cigarettes (10). Indeed, in a study examining youth attitudes and beliefs toward alternative tobacco products, Soldz and Dorsey found that, among young people, the most endorsed attitude toward bidis was that they look like joints (21). This relationship could not be examined among Canadian youth using YSS measures. To adequately examine this association, measures that distinguish use of marijuana from use of blunts should be included in surveillance of tobacco use. In addition, given the recent decline in cigarette smoking prevalence and the clustering of alcohol, tobacco, and marijuana use among youth (22), the study findings offer further support for prevention programs to target multiple risk behaviors (23).

Examination of sociodemographic characteristics indicated patterns across race/ethnicity and sex for bidi and hookah use. Youth of Asian, black, Latin, or other race/ethnicity were more likely than white youth to report ever and current use of both bidis and hookahs, and youth of Aboriginal descent were more likely to be current users of bidis and ever users of hookahs than were white youth. Although black and Hispanic race/ethnicity have been associated with bidi use among youth in the United States $(9,10)$, this finding is the first indication that an association between ethnicity and bidi use exists among Canadian youth. Although the association of black, Latin, or other race/ethnicity with bidi use mirrors that found in the United States, the association of Asian ethnicity and bidi use may be attributable to cultural traditions of Canada's large South Asian population. The association of ethnicity with hookah use has been documented $(8,13,19)$. Consistent with existing research $(8-11,19,20)$, our study also found that male respondents were more likely than female respondents to report ever and current use of bidis and hookahs. Comparison of hookah use from 2006 through 2010 showed large and significant increases among female respondents. Given that such increases are similar to the uptake of cigarette smoking by US females in the 1960s (24), tobacco control strategies should address alternative tobacco products, and further research into sex differences in the use of these substances may be warranted. 
We found that youth who are current or former smokers were more likely to report current use of bidis and hookahs than were nonsmokers. Occasional or frequent consumption of alcohol were also associated with current use of hookahs. Although these associations are consistent with the literature on co-occurrence of substance use (8$11,13,14,19)$, the exact nature of the relationship among these substances is not clear. Understanding this relationship requires further research to determine whether a particular substance serves as a gateway to other substance use or whether the substances are interrelated in some other way. Such research can be helpful to prevention programs targeting multiple risk behaviors (23). Longitudinal data are required.

Our study has limitations. First, the cross-sectional design of the study does not allow causal inferences to be drawn between use of bidis and hookahs and examined correlates or for the determination of temporality of use among the substances examined. Second, self-reported data derived from research examining substance use may be underreported. Third, the survey did not allow for the differentiation of methods pertaining to marijuana use, hindering the interpretation of associations between use of bidis and marijuana. Fourth, the study was limited to observations of co-occurrence of substance use because it examined risk of use rather than comorbid use of various substances. Finally, the analysis was limited to the representation of youth in mainstream school settings; youth who are not in school and youth who are in alternative school settings were excluded. This same limitation applies to the lack of representation of First Nation Peoples living on reserves.

The rise in hookah use warrants attention, given its increasing popularity. Efforts aimed at eliminating false perceptions of reduced harm associated with hookah use may show promise in reducing its social acceptability, especially as it becomes more prevalent. Factors associated with bidi and hookah use can help developers of prevention programs, and co-occurrence of substance use supports the development of an integrated approach to prevention that addresses multiple risk behaviors.

\section{Acknowledgments}

Dr Leatherdale is a Cancer Care Ontario Research Chair in Population Studies funded by the Ontario Ministry of Health and Long-Term Care. The Youth Smoking Survey is a product of the pan-Canadian capacity-building project funded through a contribution agreement between Health Canada and the Propel Centre for Population Health Impact at the University of Waterloo. This pan-Canadian consortium included Canadian tobacco control researchers from all provinces and provided training opportunities for university students at all levels, encouraging their involvement and growth in the field of tobacco control research. Production of this article was made possible through a financial contribution from the Ontario Tobacco Research Unit. Ms Czoli was supported with a Canadian Institutes of Health Research Training Grant in Population Intervention for Chronic Disease Prevention: A Pan-Canadian Program (grant no. 53893), the Ontario Tobacco Research Unit Ashley Studentship for Research in Tobacco Control, and the Ontario Graduate Scholarship.

\section{Author Information}

Corresponding Author: Scott T. Leatherdale, PhD, School of Public Health and Health Systems, University of Waterloo, 200 University Ave, Waterloo, ON, Canada N2L 3G1. Telephone: 1-519-888-4567, ext 37812. E-mail: sleather@uwaterloo.ca.

Author Affiliations: Christine D. Czoli, Vicki Rynard, University of Waterloo, Waterloo, ON, Canada

\section{References}

1. Warren CW, Lea V, Lee J, Jones NR, Asma S, McKenna M. Change in tobacco use among 13-15 year olds between 1999 and 2008: findings from the Global Youth Tobacco Survey. Glob Health Promot 2009;16(2 Suppl):38-90. CrossRef 惫 PubMed 图

2. Canadian Tobacco Use Monitoring Survey overview of historical data. 1999-2010. Health Canada; 2011. http://www.hc-sc.gc.ca/hc-ps/tobac-tabac/research-recherche/stat/_ctums-esutc_2010/ann-histoeng.php\#tab8. Accessed December 5, 2012.

3. Akl EA, Gaddam S, Gunukula SK, Honeine R, Jaoude PA, Irani J. The effects of waterpipe tobacco smoking on health outcomes: a systematic review. Int J Epidemiol 2010;39(3):834-57. CrossRef 處 PubMed 图

4. Malson JL, Sims K, Murty R, Pickworth WB. Comparison of the nicotine content of tobacco used in bidi and

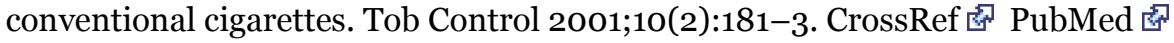

5. Yen KL, Hechavarria E, Bostwick SB. Bidi cigarettes: an emerging threat to adolescent health. Arch Pediatr Adolesc Med 2000;154(12):1187-9. PubMed 通

6. Martinasek MP, McDermott RJ, Martini L. Waterpipe (hookah) tobacco smoking among youth. Curr Probl Pediatr Adolesc Health Care 2011;41(2):34-57. CrossRef 图 PubMed 还 
7. Wray RJ, Jupka K, Berman S, Zellin S, Vijaykumar S. Young adults' perceptions about established and emerging tobacco products: results from eight focus groups. Nicotine Tob Res 2012;14(2):184-90. CrossRef 虚 PubMed 图

8. Chan WC, Leatherdale ST, Burkhalter R, Ahmed R. Bidi and hookah use among Canadian youth: an examination of data from the 2006 Canadian Youth Smoking Survey. J Adolesc Health 2011;49(1):102-4. CrossRef PubMed $^{2}$ 通

9. Delnevo CD, Pevzner ES, Hrywna M, Lewis MJ. Bidi cigarette use among young adults in 15 states. Prev Med 2004;39(1):207-11. CrossRef 图 PubMed 莤

10. Delnevo CD, Hrywna M. The relationship of cigars, marijuana, and blunts to adolescent bidi use. Public Health Rep 2006;121(5):603-8. PubMed 总

11. Tercyak KP, Audrain J. Psychosocial correlates of alternate tobacco product use during early adolescence. Prev Med 2002;35(2):193-8. CrossRef 因 PubMed 空

12. Maziak W. The global epidemic of waterpipe smoking. Addict Behav 2011;36(1-2):1-5. CrossRef 逄 PubMed 芯

13. Bover Manderski MT, Hrywna M, Delnevo CD. Hookah use among New Jersey youth: associations and changes over time. Am J Health Behav 2012;36(5):693-9. CrossRef 图 PubMed 图

14. Smith JR, Novotny TE, Edland SD, Hofstetter CR, Lindsay SP, Al-Delaimy WK. Determinants of hookah use among high school students. Nicotine Tob Res 2011;13(7):565-72. CrossRef \& $^{*}$ PubMed 图

15. University of Waterloo. Youth Smoking Survey (YSS): 2010/2011 YSS microdata user guide. Propel Centre for Population Health Impact; 2011. http://yss.uwaterloo.ca/results/yss10_user_guide_english_ver5_20120411.pdf. Accessed December 5, 2012.

16. Elton-Marshall T, Leatherdale ST, Manske SR, Wong K, Ahmed R, Burkhalter R. Research methods of the Youth Smoking Survey (YSS). Chronic Dis Inj Can 2011;32(1):47-54. PubMed 店

17. Youth Smoking Survey questionnaire archive. Propel Centre for Population Health Impact, University of Waterloo; 2011.http://www.yss.uwaterloo.ca/_global/documents/YSS12_qq_mod_B_english.pdf. Accessed December 10, 2012.

18. Cole AG, Leatherdale ST, Burkhalter R. An examination of different smoking patterns among Canadian youth: new insight for tobacco control programming. Addict Behav 2013;38(3):1610-5. CrossRef i PubMed 逄

19. Sterling KL, Mermelstein R. Examining hookah smoking among a cohort of adolescent ever smokers. Nicotine Tob Res 2011;13(12):1202-9. CrossRef 鹿 PubMed 芯

20. Dugas E, Tremblay M, Low NC, Cournoyer D, O'Loughlin J. Water-pipe smoking among North American youth. Pediatrics 2010;125(6):1184-9. CrossRef 图 PubMed tis

21. Soldz S, Dorsey E. Youth attitudes and beliefs toward alternative tobacco products: cigars, bidis, and kreteks. Health Educ Behav 2005;32(4):549-66. CrossRef $\mathbf{w}^{2}$ PubMed 图

22. Leatherdale ST, Hammond D, Ahmed R. Alcohol, marijuana, and tobacco use patterns among youth in Canada. Cancer Causes Control 2008;19(4):361-9. CrossRef 逄 PubMed 逢

23. Leatherdale ST, Ahmed R. Alcohol, marijuana, and tobacco use among Canadian youth: do we need more multisubstance prevention programming? J Prim Prev 2010;31(3):99-108. CrossRef 图 PubMed 图

24. Preventing tobacco use among youth and young adults: a report of the Surgeon General. US Department of Health and Human Services, Centers for Disease Control and Prevention, National Center for Chronic Disease Prevention and Health Promotion, Office on Smoking and Health; 2012.

http://www.cdc.gov/tobacco/data_statistics/sgr/2001/complete_report/index.htm. Accessed December 10, 2012.

\section{Tables}

Table 1. Characteristics of Youth in Grades 9-12, by Bidi and Hookah Use, Youth Smoking Survey, Canada, 2010 ${ }^{a}$

\begin{tabular}{|l|r|r|r|r|}
\hline \multirow{2}{*}{$\begin{array}{l}\text { Sample } \\
\text { Characteristics }\end{array}$} & $\begin{array}{c}\text { Ever Use of Bidis } \\
(\mathbf{n = 1 , 6 0 1 , 4 0 0 )}\end{array}$ & $\begin{array}{c}\text { Current Use of Bidis } \\
(\mathbf{n}=\mathbf{1 , 5 7 0 , 4 0 0 )}\end{array}$ & $\begin{array}{c}\text { Ever Use of Hookahs } \\
(\mathbf{n}=\mathbf{1 , 6 0 1 , 4 0 0 )}\end{array}$ & $\begin{array}{c}\text { Current Use of } \\
\text { Hookahs }(\mathbf{n}= \\
\mathbf{1 , 5 7 0 , 4 0 0})^{\mathbf{b}}\end{array}$ \\
\hline All Youth & 1.8 & 1.0 & 10.1 & 4.0 \\
\hline
\end{tabular}




\begin{tabular}{|c|c|c|c|c|}
\hline \multirow[b]{2}{*}{$\begin{array}{l}\text { Sample } \\
\text { Characteristics }\end{array}$} & \multicolumn{4}{|c|}{ Prevalence (\%) } \\
\hline & $\begin{array}{l}\text { Ever Use of Bidis } \\
(n=1,601,400)^{b}\end{array}$ & $\begin{array}{l}\text { Current Use of Bidis } \\
(n=1,570,400)^{b}\end{array}$ & $\begin{array}{l}\text { Ever Use of Hookahs } \\
(n=1,601,400)^{b}\end{array}$ & $\begin{array}{c}\text { Current Use of } \\
\text { Hookahs }(n= \\
1,570,400)^{b}\end{array}$ \\
\hline \multicolumn{5}{|l|}{ Grade level } \\
\hline 9th & 1.7 & 1.1 & 5.4 & 2.2 \\
\hline 10th & 1.8 & 0.6 & 7.4 & 3.0 \\
\hline 11th & 2.1 & 1.2 & 12.0 & 4.6 \\
\hline 12th & 1.8 & 1.1 & 15.8 & 6.4 \\
\hline \multicolumn{5}{|l|}{ Province $^{c}$} \\
\hline Atlantic Canadad & 2.9 & 1.6 & 6.8 & 3.5 \\
\hline Quebec & $N A^{f}$ & $N A^{f}$ & 12.8 & 3.9 \\
\hline Ontario & 1.1 & 0.6 & 8.7 & 4.1 \\
\hline Prairiese & 2.7 & 1.7 & 10.3 & 3.6 \\
\hline British Columbia & 1.9 & 1.1 & 11.9 & 4.6 \\
\hline \multicolumn{5}{|l|}{ Race/ethnicity } \\
\hline White & 1.3 & 0.4 & 10.1 & 3.6 \\
\hline Black, Latin, other & 4.4 & 3.2 & 14.5 & 6.9 \\
\hline Asian & 1.4 & 1.1 & 5.4 & 2.3 \\
\hline Aboriginal & 2.4 & 1.8 & 9.4 & 4.5 \\
\hline \multicolumn{5}{|c|}{ Cigarette smoking statusg } \\
\hline Nonsmoker & 0.9 & 0.4 & 6.4 & 2.1 \\
\hline Former & 5.4 & $N A^{f}$ & 48.1 & NAf \\
\hline Current & 11.1 & 6.6 & 40.3 & 21.2 \\
\hline \multicolumn{5}{|c|}{ Ever use of flavored tobacco productsg } \\
\hline No & 0.3 & 0.2 & 2.4 & 0.7 \\
\hline Yes & 6.1 & 3.2 & 32.1 & 13.8 \\
\hline \multicolumn{5}{|c|}{ Current use of flavored bidig } \\
\hline No & NA & 0.3 & 9.2 & 3.2 \\
\hline Yes & NA & 74.0 & 69.2 & 65.9 \\
\hline \multicolumn{5}{|c|}{ Current use of flavored tobacco in a water pipeg } \\
\hline No & 1.1 & 0.3 & NA & 1.5 \\
\hline Yes & 25.0 & 21.3 & NA & 80.6 \\
\hline \multicolumn{5}{|c|}{ Marijuana use statusg } \\
\hline Nonuser & 0.3 & 0.1 & 2.6 & 0.7 \\
\hline Occasional user & 2.0 & 1.1 & 18.2 & 5.7 \\
\hline Frequent user & 9.9 & 5.3 & 42.6 & 20.6 \\
\hline \multicolumn{5}{|c|}{ Current alcohol useg } \\
\hline Nondrinker & 0.4 & 0.2 & 2.0 & 0.6 \\
\hline Occasional drinker & 1.4 & 0.4 & 12.0 & 4.3 \\
\hline Frequent drinker & 6.8 & 4.2 & 29.8 & 13.2 \\
\hline
\end{tabular}


Preventing Chronic Disease I Bidi and Hookah Use Among Canadian Youth: Findings Fr... Page 8 of 10

Abbreviation: NA, not applicable.

a Analyses were conducted using weighted data.

b Weighted population estimates. Per Health Canada guidelines (16), weighted population estimates are rounded to the nearest hundred.

c It is illegal to sell or give tobacco to anyone under the age of 18 in the provinces of Alberta, Manitoba, Quebec, and Saskatchewan, and under the age of 19 in the provinces of British Columbia, Newfoundland and Labrador, Nova Scotia, Ontario, and Prince Edward Island.

d Atlantic Canada (Prince Edward Island, Nova Scotia, and Newfoundland and Labrador).

e Prairies (Alberta, Saskatchewan, and Manitoba).

f Data were suppressed because the unweighted sample size was less than 30.

g See Methods section for definitions of characteristics.

Table 2. Prevalence of Bidi and Hookah Use Among Youth in Grades 9-12, Youth Smoking Survey (YSS), Canada, 2006-2010a

\begin{tabular}{|c|c|c|c|c|}
\hline Prevalence, \% & 2006 & 2010 & $\%$ Change $^{b}$ & $P$ Valuec \\
\hline \multicolumn{5}{|l|}{ Ever use } \\
\hline Total & $n=1,574,000^{d}$ & $n=1,601,400 d$ & NA & NA \\
\hline Bidi & 2.2 & 1.8 & -18 & .002 \\
\hline Hookah & 9.5 & 10.1 & 6 & .02 \\
\hline Female & $n=761,600^{d}$ & $n=777,700^{d}$ & NA & NA \\
\hline Bidi & 1.5 & 1.0 & -33 & $<.001$ \\
\hline Hookah & 7.7 & 8.5 & 10 & .009 \\
\hline Male & $n=812,400^{d}$ & $n=823,700^{d}$ & NA & NA \\
\hline Bidi & 2.9 & 2.6 & -10 & .17 \\
\hline Hookah & 11.2 & 11.6 & 4 & .31 \\
\hline \multicolumn{5}{|l|}{ Current use } \\
\hline Total & $n=1,531,900^{d}$ & $n=1,570,400^{d}$ & NA & NA \\
\hline Bidi & 0.8 & 1.0 & 25 & .06 \\
\hline Hookah & 3.9 & 4.0 & 3 & .37 \\
\hline Female & $n=742,400 d$ & $n=766,800^{d}$ & NA & NA \\
\hline Bidi & 0.4 & 0.6 & 50 & .007 \\
\hline Hookah & 2.5 & 2.9 & 16 & .02 \\
\hline Male & $n=789,500 d$ & $n=803,700^{d}$ & NA & NA \\
\hline Bidi & 1.2 & 1.3 & 8 & .57 \\
\hline Hookah & 5.1 & 5.0 & -2 & .65 \\
\hline
\end{tabular}

Abbreviations: NA, not applicable.

a Analyses were conducted using weighted data.

b Percentage change from 2006 through 2010 (percentage in 2006 minus the percentage in 2010 divided by the percentage in 2006).

c Calculated by using $\mathrm{x}^{2}$ tests.

d Weighted population estimates. Per Health Canada guidelines, weighted population estimates are rounded to the nearest hundred. 
Preventing Chronic Disease I Bidi and Hookah Use Among Canadian Youth: Findings Fr... Page 9 of 10

Table 3. Multivariate Logistic Regression Analyses Examining Factors Associated With Bidi and Hookah Use Among Youth in Grades 9-12, Youth Smoking Survey, Canada, 2010 a

\begin{tabular}{|c|c|c|c|c|c|c|c|c|}
\hline \multirow[b]{3}{*}{$\begin{array}{l}\text { Characteristic or } \\
\text { Behavior }\end{array}$} & \multicolumn{2}{|c|}{ Model $\mathbf{1}^{\mathbf{b}}$} & \multicolumn{2}{|c|}{ Model 2c } & \multirow{2}{*}{\multicolumn{2}{|c|}{$\begin{array}{c}\text { Model } 3^{d} \\
\text { Ever Use of } \\
\text { Hookahs }\end{array}$}} & \multirow{2}{*}{\multicolumn{2}{|c|}{$\begin{array}{c}\text { Model } 4^{e} \\
\begin{array}{c}\text { Current Use of } \\
\text { Hookahs }\end{array}\end{array}$}} \\
\hline & \multicolumn{2}{|c|}{ Ever Use of Bidis } & \multicolumn{2}{|c|}{ Current Use of Bidis } & & & & \\
\hline & $\begin{array}{c}\text { ORf }(95 \% \\
\text { CI })\end{array}$ & $\begin{array}{c}P \\
\text { Valueg }\end{array}$ & $\begin{array}{c}\text { ORf }^{f}(95 \% \\
\text { CI })\end{array}$ & $\begin{array}{c}P \\
\text { Valueg }\end{array}$ & $\begin{array}{c}\text { ORf }^{f}(95 \% \\
\text { CI })\end{array}$ & $\begin{array}{c}P \\
\text { Valueg }\end{array}$ & $\begin{array}{c}\text { ORf }^{f}(95 \% \\
\text { CI })\end{array}$ & $\begin{array}{c}P \\
\text { Valueg }\end{array}$ \\
\hline \multicolumn{9}{|l|}{ Sex } \\
\hline Female & \multicolumn{8}{|c|}{1 [Reference] } \\
\hline Male & $\begin{array}{r}2.5(2.0- \\
3.1)\end{array}$ & $<.001$ & $\begin{array}{r}1.5(1.1- \\
2.1)\end{array}$ & .01 & $\begin{array}{r}1.1(1.0- \\
1.2)\end{array}$ & .16 & $\begin{array}{r}1.3(1.1- \\
1.4)\end{array}$ & $<.01$ \\
\hline \multicolumn{9}{|l|}{ Race/ethnicity } \\
\hline White & \multicolumn{8}{|c|}{1 [Reference] } \\
\hline Black, Latin, other & $\begin{array}{r}4.6(3.7- \\
5.8)\end{array}$ & $<.001$ & $\begin{array}{r}15.6(10.8- \\
22.5)\end{array}$ & $<.001$ & $\begin{array}{r}2.2(1.9- \\
2.5)\end{array}$ & $<.001$ & $\begin{array}{r}2.4(2.1- \\
2.9)\end{array}$ & $<.001$ \\
\hline Asian & $\begin{array}{r}3.2(2.2- \\
4.7)\end{array}$ & $<.001$ & $\begin{array}{r}14.9 \text { (8.9- } \\
24.9)\end{array}$ & $<.001$ & $\begin{array}{r}1.5(1.3- \\
1.8)\end{array}$ & $<.001$ & $\begin{array}{r}1.5(1.2- \\
2.0)\end{array}$ & $<.01$ \\
\hline Aboriginal & $\begin{array}{r}1.1(0.8- \\
1.7)\end{array}$ & .56 & $\begin{array}{r}3.3(1.9- \\
5.7)\end{array}$ & $<.001$ & $\begin{array}{r}0.6(0.5- \\
0.7)\end{array}$ & $<.001$ & $\begin{array}{r}0.8(0.6- \\
1.1)\end{array}$ & .20 \\
\hline \multicolumn{9}{|c|}{ Cigarette smoking statush } \\
\hline Nonsmoker & \multicolumn{8}{|c|}{1 [Reference] } \\
\hline Former & $\begin{array}{r}1.9(1.2- \\
3.1)\end{array}$ & .01 & $0.2(0-0.7)$ & .02 & $\begin{array}{r}5.5(4.4- \\
6.9)\end{array}$ & $<.001$ & $\begin{array}{r}3.3(2.5- \\
4.4)\end{array}$ & $<.001$ \\
\hline Current & $\begin{array}{r}4.1(3.3- \\
5.2)\end{array}$ & $<.001$ & $\begin{array}{r}6.7(4.8- \\
9.5)\end{array}$ & $<.001$ & $\begin{array}{r}2.4(2.1- \\
2.6)\end{array}$ & $<.001$ & $\begin{array}{r}3.0(2.5- \\
3.5)\end{array}$ & $<.001$ \\
\hline \multicolumn{9}{|c|}{ Marijuana use statush } \\
\hline Nonuser & \multicolumn{8}{|c|}{1 [Reference] } \\
\hline Occasional user & $\begin{array}{r}4.9(3.3- \\
7.2)\end{array}$ & $<.001$ & $\begin{array}{r}23.9(10.8- \\
53.0)\end{array}$ & $<.001$ & $\begin{array}{r}4.8(4.2- \\
5.4)\end{array}$ & $<.001$ & $\begin{array}{r}5.6(4.4- \\
7.1)\end{array}$ & $<.001$ \\
\hline Frequent user & $\begin{array}{r}13.1(9.0- \\
19.1)\end{array}$ & $<.001$ & $\begin{array}{r}50.4(22.9- \\
111.0)\end{array}$ & $<.001$ & 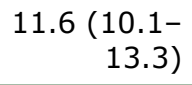 & $<.001$ & $\begin{array}{r}14.1(11.1- \\
18.0)\end{array}$ & $<.001$ \\
\hline \multicolumn{9}{|c|}{ Current alcohol use statush } \\
\hline Nondrinker & \multicolumn{8}{|c|}{1 [Reference] } \\
\hline Occasional drinker & $\begin{array}{r}1.3(0.9- \\
2.0)\end{array}$ & .16 & $\begin{array}{r}0.4(0.2- \\
0.7)\end{array}$ & $<.01$ & $\begin{array}{r}2.5(2.1- \\
3.0)\end{array}$ & $<.001$ & $\begin{array}{r}2.8(2.1- \\
3.8)\end{array}$ & $<.001$ \\
\hline Frequent drinker & $\begin{array}{r}2.2(1.5- \\
3.4)\end{array}$ & $<.001$ & $\begin{array}{r}1.3(0.8- \\
2.3)\end{array}$ & .29 & $\begin{array}{r}3.3(2.8- \\
4.0)\end{array}$ & $<.001$ & $\begin{array}{r}3.6(2.7- \\
5.0)\end{array}$ & $<.001$ \\
\hline
\end{tabular}

Abbreviations: OR, odds ratio; CI, confidence interval.

a Analyses were conducted using weighted data.

b Model 1: 1 = yes $(n=550), 0=$ no $(n=27,123)$.

c Model 2: $1=$ yes $(n=264), 0=$ no $(n=26,937)$.

d Model 3: $1=$ yes $(n=2,166), 0=$ no $(n=25,507)$.

e Model 4: 1 =yes $(n=881), 0=$ no $(n=26,320)$.

$f$ Odds ratios adjusted for all other variables in the table and controlling for grade and province.

$g$ Calculated by using Wald $x^{2}$ tests.

$\mathrm{h}$ See Methods section for definitions of characteristics. 
The opinions expressed by authors contributing to this journal do not necessarily reflect the opinions of the U.S. Department of Health and Human Services, the Public Health Service, the Centers for Disease Control and Prevention, or the authors' affiliated institutions.

The RIS file format is a text file containing bibliographic citations. These files are best suited for import into bibliographic management applications such as EndNote $\mathbf{s}^{\mathrm{s}}$, Reference Manager download is available at each application's web site.

For Questions About This Article Contact pcdeditor@cdc.gov

Page last reviewed: May 09, 2013

Page last updated: May 09, 2013

Content source: National Center for Chronic Disease Prevention and Health Promotion

Centers for Disease Control and Prevention 1600 Clifton Rd. Atlanta, GA 30333, USA

80o-CDC-INFO (800-232-4636) TTY: (888) 232-6348 - Contact CDC-INFO 